\title{
A Strategy for English Reading Teaching-Based on Vocabulary, Grammar and Logic
}

\author{
Yu Peng \\ School of Foreign Languages, Sichuan University of Science and Engineering, Yibin, China
}

\begin{abstract}
English Reading" is a professional compulsory course combining theory with practice. This course covers English language knowledge, culture and literature knowledge, national knowledge, cross-cultural communication knowledge, basic knowledge of humanities, social sciences and natural sciences, etc., aiming to improve students' reading efficiency and ability to obtain main information, especially text appreciation, rhetoric and critical thinking ability. The task of the lesson is to cultivate students' ability of discourse analysis, semantic appreciation, logical thinking, independent thinking and proficient communication, so as to make them become "application-oriented talents" of high-quality and with innovative consciousness and creative ability". The study aimed to correlate the reading comprehension of English linguistic students, then inform some pedagogical implications for the teaching of reading comprehension (Cuc Thi Kim Pham, 2017). Through the data analysis of an authoritative reading test officially organized by the university, the author found that a large proportion of students in sophomore year failed to perform well in the test and did not demonstrate excellent reading skills. The reasons are as follows: firstly, the "teacher-led role" is neglected in reading teaching; Secondly, students ignore discourse analysis in reading; thirdly, the students' understanding of vocabulary is limited to the meaning of completely equivalent Chinese; Fourth: Grammatical awareness is not strong. The author finds out the problems that students have in reading, and combines relevant cases to conduct in-depth discussions on these issues.
\end{abstract}

Index Terms — reading comprehension, teacher-led, vocabulary, grammar, logic

\section{A New Perspective of "English Reading": The Task and Function}

English reading is a professional compulsory course combining theory with practice. As the new era puts forward higher requirements for us, as teachers, we should guide students to change the learning methods of reading lessons in the past. They should not only focus on vocabulary, grammar, but also pay attention to the overall structure of the article, the logical connection between paragraphs, and the denotative and connotative meaning of words and lines, and moreover the rhetoric and idiom expressions should not be neglected either.

It is important for students to pay attention to the connection between the topic sentence of the development of paragraph, the connection between the central idea of the article and macroscopic framework of paragraph expansion and text construction, and the argument relationship between the details and the subject. Most importantly, social value implied behind the author's language should be noticed. Thus, English reading course could authentically be a transitional stage for students' cognitive progress.

Reading plays an important role in the process of language learning and in the modern society, teachers can apply the multimedia technology to assist the reading instruction (Liming Han, 2010). "Syllabus for English Majors in Colleges and Universities" points out that the purpose of English reading lesson is to cultivate students' English reading comprehension ability and improve students' reading speed; to cultivate students' ability to meticulously observe language and improve their ability of analytical thinking, induction, reasoning and other logical thinking skills; Therefore, textbooks should use a wide range of reading materials to provide students with a wide range of language and cultural materials to expand the students' knowledge and enhance their English language sense and students' interest in learning (XueMei Duan, Li-Hua Song, 2007). The extensive reading course requires students to read a lot, so the guiding role of the teacher becomes very important, which is not only reflected in the guidance of teachers on the structure of knowledge and the guidance of classroom activities, but also includes teacher's guiding students how to choose extracurricular reading materials in order to effectively cultivate their reading interest, expand their vocabulary and so on.

\section{Data ANALysis of Students' English Reading AbILITy}

The first semester of the 2018-2019 school year, from 14:45 to 16:45 on January 8, 2019, the sophomore students of the School of Foreign Languages, Sichuan University of Science \& Engineering, conducted an examination of English reading, which was officially organized by the university. The relevant information of the test papers is as follows:

Principles of English Reading Test

The test papers are divided into four sections: basic knowledge, basic reading theory, theoretical application, and expanding ability. The focus and score ratio of each section of the test paper is: 
- Fill in the blanks with the correct forms of the given words. (20\%)

This section examines the basic knowledge of students, with a focus on basic grammar knowledge, vocabulary knowledge, and the use of fixed phrases.

- Synonyms and Lexical Substitution (10\%)

The detail is that in each of the following sentences, there is one underlined word, and students should decide which of the four meanings can replace the underlined word and fits the sentence best. This section examines students' ability of vocabulary replacement and the ability to use synonyms, which can test students' vocabulary levels and their ability to use English vocabulary.

- Reading Comprehension (40\%)

This section consists of four passages and twenty questions, most of which is to test whether the students can analyze the logic of the articles and get the correct understanding. This section examines the basic ability of the student's paragraph extension, the ability to master the topic sentence of a paragraph; examine whether the student can quickly obtain useful information in the text.

- Translation (30\%)

This section mainly examines the students' mastery of the content of the articles they have learned, as well as the students' language output ability, and examines whether they can grasp the key information of the article.

In total, 242 sophomores took the exam and the result of the exam is shown below:

TABLE I

RESULT OF THE EXAM

\begin{tabular}{|c|c|c|c|c|c|c|c|c|c|}
\hline Score Divisions & $0 \sim 29$ & $30 \sim 59$ & $60 \sim 69$ & $70 \sim 79$ & $80 \sim 89$ & $90 \sim 100$ & $\begin{array}{c}\text { The } \\
\text { highest }\end{array}$ & $\begin{array}{c}\text { The } \\
\text { lowest }\end{array}$ & Average \\
\cline { 1 - 8 } Number & 0 & 5 & 21 & 57 & 129 & 30 & 96 & 46 & 80.9 \\
\hline percentage & 0.0 & 2.1 & 8.7 & 23.6 & 53.3 & 12.4 & & & \\
\hline
\end{tabular}

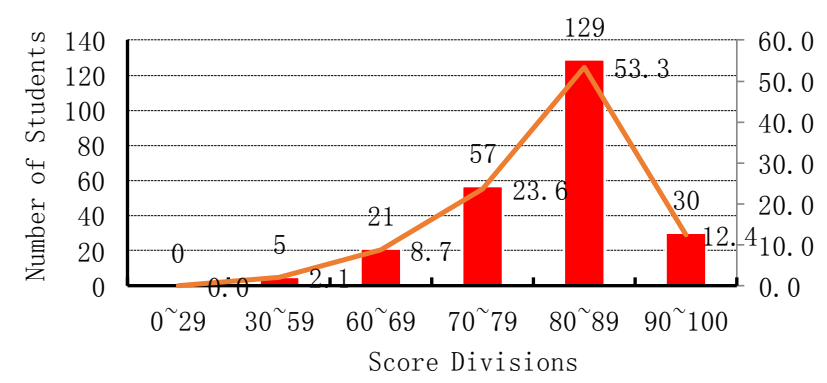

Number
— Percentage

The analysis of the results of the reading test of the whole grade is as follows:

- Overall performance status: the analysis of students' test performance is shown in the figure above, showing a normal distribution of performance; That is to say, the average score of 80-89 accounts for the majority, while the rest of the scores decrease successively to both sides, among which the underachieving students accounted for 34 percent of the total.

- The author checks the papers of $34 \%$ of the students and finds that a large proportion of these students have lower scores in the vocabulary and reading comprehension, reflecting that the students are not well versed in the understanding of words in specific contexts, and that they cannot analyze clearly the logic of the articles so as to get the correct understanding, to master the topic sentence of a paragraph, and to obtain useful information in the text. Furthermore, they did not score high in the "speed reading" part, and a few students did poorly in this part, indicating that students need to further strengthen the text understanding and important grammar, so as to improve the effectiveness of information input in reading.

- It reflects the problem of teachers' teaching: teachers seldom explain reading methods and skills in teaching, fail to allow students to carry out a lot of discourse analysis due to the limitation of class time, which makes the lesson lack of effective teacher-led guidance.

\section{The Balance between English Teachers' "Leading Role" and Students' "Subject Status"}

Compared with other subjects, the particularity of English learning determines that English classroom teaching should pay more attention to students' independent practice, that is, students' "subject status".

However, the content of English reading texts involves all aspects of social life; and at the same time, the styles are diverse, including profound literary works, practical expository articles, news and advertisements, excellent narrative works and logical argumentative articles, which are all-inclusive and cover a wide range of knowledge. This requires teachers to have a wide range of life experience and adequate knowledge reserves, and play a "leading" role in the 
English reading class, because if separated from the teacher's leading role, the student's "subject status" will be restrained: compared with teachers, the cognitive structure of students is relatively weak, and the acquisition of important knowledge is not targeted, so in the face of a large and extensive knowledge system, it is easy for students to get "selective loss" (Zhao Ye, 2010). Then what does the teachers' "Leading Role" mean? The next part serves as case studies to show the function of a teacher in English reading class.

\section{CAse Studies of English Reading TEACHing}

\section{A. Case Study 1: Teacher's Leading in Students' Grammar Learning}

In the book "Reading Course" (second edition), edited by Weidong Dai, there is a short passage like this:

UN peacekeeping operations are not an enforcement tool. However they may use force at the tactical level, with the authorization of the Security Council, if acting in self-defense and defense of the mandate In certain volatile situations, the Security Council has given UN peacekeeping operations "robust" mandates authorizing them to "use all necessary means" to deter forceful attempts to disrupt the political process, protect civilians under imminent threat of physical attack and/or assist the national authorities in maintaining law and order. Although on the ground they may sometimes appear similar, robust peacekeeping should not be confused with peace enforcement, as envisaged under Chapter VII of the United Nations Charter.

And then there is a question about the passage:

Question: The passage suggests that robust peacekeeping can use all necessary means for all the following purposes EXCEPT for?
A. protecting civilians
B. maintaining law and older
C. disrupting the political process

Most of my students just get confused by this question, because they think that all of the three choices are right the purpose of "use all necessary means". The reason why they cannot make a right choice is that they do not understand the relationship between "to deter..." and "to disrupt...". They mistakenly think "to disrupt..." is adverbs of purpose, but actually "to deter forceful attempts" is the adverbs of purpose of the sentence, and "to disrupt the political process" is just a modifier, an attribute, of the noun "attempts". That is to say, the purpose of "use all necessary means" is to deter "disrupt the political process", instead of to "disrupt the political process".

Then from a theoretic level, the teacher should let the students know one important principle in reading English article, especially when facing the difficult and long sentences, which is the relationship between the modifiers and the being-modified. Actually, in English there are and only are two sentence structures--the first: (subject) + predicate-verb + (object); the second: subject + link-verb + predicative. And all of the other sentence constituents are just the modifiers. With such principle in their mind, the students will find the difficult and long sentences in English reading is not a big problem. For example, in an article "American Dream" whose author is Ina Corinne Brown, there is a very difficult and long sentence shown in italic as follows:

To Americans, industriousness, thrift, and ambition are positive values. We encourage our children to be competitive, to get ahead, to make money, to acquire possessions. In games and in business alike the aim is to win the game, the trophy, the contract. We go in for labor-saving devices, gadgets, speed, and short-cuts. We think every young couple should set up a home of their own, and we pity the couple who must share their home with a parent, let alone with other relatives. Actually, of course, not all Americans hold all these values, and those who do may hold other, and at times contradictory, values that affect their ways of behaving. In the main, however, the collective expectation of our society is that these are desirable goals, and the individual, whatever his personal inclination, is under considerable pressure to conform.

As for the sentence in italic, most of my students do not even know the sentence constituents, not to mention the meaning, the reason of which lies in the lack of grammar knowledge. When students are facing such long and difficult sentence in reading, the teacher should guide the students to analyze the sentence structure with the grammatical principle mentioned above. In that sentence, "Actually, of course" is adverbial modifier, "not all Americans hold all these values" is a sentence, and "those who do ... ways of behaving" is another sentence connected by a conjunction "and". Then the students will find that the first sentence is simple, with "not all Americans" as the subject, "hold" as the predicate verb, and "all these values" as the object; they will find the most difficult is about the second sentence "those who do may hold other, and at times contradictory, values that affect their ways of behaving." Then the teacher should guide the students firstly confirm whether the sentence structure is "(subject) + predicate-verb + (object)" or "subject + link-verb + predicative", and then they will easily tell it is the first because there is no predicative in the sentence, and next guide the students find out the subject, predicate-verb, and object. Therefore, they will know: "those" is subject; "who do" is an attributive clause modifying the subject; and here "do" is a pronoun means "hold all these values" in the first part of the sentence; "may hold" is the predicate-verb, "other, and at times contradictory, values" is actually a parallel-object of "hold", which means "other values and even contradictory values"; "hat affect their ways of behaving" an attributive clause modifying the two parallel objects. So the students will get clearly that the main structure is just like this "those hold other and contradictory values", which is easy to understand. 


\section{B. Case Study 2: Teacher's Leading in Students'Vocabulary Learning}

In one of my papers "A Special Strategy for Practical English Teaching: to Find Interesting Linguistic Phenomena of English" published in SSRG International Journal of Humanities and Social Science, Volume 5 Issue 5, 2018, there is a case about students' misunderstanding of some special English words: in the fourteenth paragraph of the article "The Changing Sino-American Relationship", from the unit seven of the book "Reading Course" (second edition), edited by Weidong Dai, there is a sentence like this:

And it is exposing its forces to multi-national military exercises outside its own borders, while undertaking internationally sanctioned operations.

The word "sanction" is special, because it has two meanings and most importantly the two meanings are totally opposite.

"sanction"

- official orders or laws stopping trade, communication etc. with another country, as a way of forcing its leaders to make political changes; measures taken by countries to restrict trade and official contact with a country that has broken international law; a form of punishment that can be used if someone disobeys a rule or law

- formal official permission, approval, or acceptance: if someone in authority sanctions an action or practice, they officially approve of it and allow it to be done

Facing such a context, if the students just know that the meaning of "sanctioned" is a form of punishment, the information they can get in the paragraph could be "China has focused on modern technology and weapon systems to take part in some unreasonable multi-national military exercises which are disagreed by the world"; on the contrary, if students just know the meaning of the special word "sanctioned" is the second one (formal official permission, approval), the information they can get could be "China has tried so hard to upgrade modern technology and weapon systems in order to make contribution to the righteous multi-national military exercises which are supported by the world." So from the analysis above, we can see that the totally opposite meaning of the word "sanction" may cause serious misunderstanding for students and even make some students make big mistake in getting key information from the article. It is crucial that teachers make a summery, or even conduct relevant research on such special linguistic phenomenon to help students know that there is such a linguistic phenomenon: auto-antonyms, which could help students to make sure which meaning of the word is more suitable according to certain context, so as to help them to get the correct information and avoid making serious mistakes in understanding the whole article (Peng Yu, 2018).

For more instance, looking up this word "dust" in the Collins English Dictionary, you will find its meanings are as follow:

"When you dust something such as furniture, you remove dust from it, usually using a cloth" or "If you dust something with a fine substance such as powder or if you dust a fine substance onto something, you cover it lightly with that substance", two totally opposite behaviors. Dust is part of a series of noun-verb conversions related to coverings of things. If the noun gives a covering that is natural to the thing, then the verb means remove the covering. If the covering is imposed, the verb means put the covering on.

\section{Case Study 3: Teacher's Leading in Students' Logic Learning}

The book "Reading Course" (second edition), edited by Weidong Dai is commonly used in English reading in many universities, but most of the articles of this book is from foreign authors (or even some unheard-of writers), foreign newspapers and foreign websites, so it is considerably difficult to find relevant analysis, exploration and some useful background information. What is worse is that, according to many students in our university, teachers just ask students to find in article the answer to some exercise questions in the book, and seldom refer to the text analysis. Therefore, there is a common situation for students that they can choose correctly the answers to some questions, but they just do not know what the article is all about, the reason of which lies in that students cognitive structure is relatively limited, so they cannot understand how the paragraphs are developed, how the author uses details to support the subject sentence, and how the subject sentences support the topic of the article; they do not know what is the logical connection between paragraphs, and the denotative and connotative meaning of words and lines, etc. Therefore, the teacher's proper guidance is crucial.

For example, the article "The Changing Sino-American Relationship" by Shahid R. Siddiqi in 2009 is so difficult that many students find it is too hard to understand it. And at this time, the teacher should tell them some difficult but important information: the logical connection between paragraphs. The author use first two paragraphs to tell the background information of Sino-American relationship: changed from "adversarial policies" in Cold War into today's "close bilateral, mutually beneficial economic partnership" because of "Kissinger's initiative of visiting Beijing"; the next two paragraphs tell that today's relationship is conducive to both countries; then comes the key information: paragraph five and the next paragraph's first sentence are actually the turning point, that is America's economic crisis adversely impacted China, making China start to find alternative solution to decrease the dependence on US and the risk from US dollar, which is the main content of the next part; then from paragraph ten to fourteen it is about China's rise in economy, politics and military, which naturally lead to the next part that "China's taking its place among super powers" forms a new strategic basis for closer Sino-US relations; after that, the first word in paragraph eighteen "But..." is the turning point indicating the third change between US and China, the reason of which mainly lies in the different 
ideology; ... So, this is the logical connection between paragraphs, and this is how the author develops these paragraphs, students should know it is the "two turning points and three changes" that makes the topic: The Changing Sino-American Relationship.

Besides, reverse thinking is important for teachers in English reading teaching. English reading is actually a reverse process of English writing: you read what the author write. So if the students understand how the author write the article, they will understand clearly and quickly what is the logic of the whole article. So the teaching of types of writing is important for teachers. There are generally four types of writing: Description, Narration, Exposition and Argumentation. With the understanding that the types of the article is description, the students will quickly know the function of the article is to paint in the readers' mind a picture in words of an object, a person, place, or scene, so when they read, they will focus on the sensory details, or the senses, such as sense of taste, sight, smell, hearing, and touch. If they know the article is a narration, they will pay close attention to "when, where, why, what and how" of a thing or story. If they know they are reading an exposition essay, they will keep a watchful eye on the process of making an automobile, the solution to some problem, or the causes and effects of a thing and so on. If they know the article they are reading is an argumentation, they will concern more about the thesis statement, sub-ideas or topic sentences, supporting details and conclusion, with such a basic logic in their mind:

TABLE II.

LOGIC OF READING ARGUMENTATION ESSAY

Beginning: Presentation of Views

Body $\left\{\begin{aligned} \text { Topic sentences 1. } & \Longrightarrow \text { Supporting details } \rightleftarrows \text { Facts/Opposite } \\ \text { Topic sentences 2. } & \Longrightarrow \text { Supporting details } \rightleftarrows \text { Facts/Opposite } \\ \text { Topic sentences 3. } & \Longrightarrow \text { Supporting detail } \longrightarrow \text { Facts/Opposite }\end{aligned}\right.$

Conclusion

\section{CONClusion}

English reading is extremely important for students and effective English reading helps university students who take English as second language learn this language from a put-in way, which to a great extend helps students accumulate and have a good command of relevant knowledge soon. It is a professional compulsory course combining theory with practice and because of its complexity teachers should guide them to change the traditional learning methods of reading lessons in the past, which just focus on words-reciting, rote learning of grammar, and ignoring the overall structure of the article, the logical connection between paragraphs, and the denotative and connotative meaning of words and lines, and moreover the rhetoric and idiom expressions. First, vocabulary learning is crucial for students' language competence, which belongs to the category of basic knowledge, and it is the responsibility of teachers to design vocabulary teaching with interesting content and interactive parts to make it vivid and interesting, such as to introduce some knowledge about spoonerisms, oxymoron, malapropisms, palindrome, etc. to students, so as to make them know that not every English word has a completely equal Chinese meaning, and sometimes it has so many meanings and even opposite meanings, just like the special linguistic phenomenon: auto-antonyms mentioned above. Second, when teaching grammar, teachers have to let students know that grammar learning is not something learned just by repeating it until you remember it, instead it can be learned well by understanding the principle and meaning of it. Third, it is definitely important to cultivate students' reading logic, that is the ability of discourse analyzing, semantic appreciating, logical thinking, and critical thinking; and let them know that sometimes the deep meaning of an article cannot be found just from the words themselves superficially, instead it can be understand only by analyzing the relationship between the denotative meaning and connotative meaning, the meaning between the lines, and the meaning from the background information. Besides, the basic knowledges of reading are absolutely important, for example when teacher talks about reading logic, he or she should let the students understand that: every paragraph has a topic sentence whose position could be at the beginning, or at the end of a paragraph, or even implied between the lines; and the function all the details in a paragraph is to support the topic sentence; all of the sentences are just to serve for the topic of the title. As teachers, we should and have to take these advices into account, so as to make our students become "application-oriented talents" of high-quality and the ones with innovative consciousness and creative ability.

\section{REFERENCES}

[1] Cuc Thi Kim Pham. (2017). Reading Comprehension and Translation Performance of English Linguistics Students of Hung Vuong University: A Correlational Study. International Journal of English Language and Translation Studies, 5, 79-85

[2] Liming Han. (2010). The Advantages and the Problems of Multimedia-aided English Reading Instruction. Journal of Language Teaching and Research, 1, 320-321. 
[3] Peng Yu. (2018). A Special Strategy for Practical English Teaching: to Find Interesting Linguistic Phenomena of English. SSRG International Journal of Humanities and Social Science, 5, 13-17

[4] XueMei Duan, Li-Hua Song. (2007). Attach Importance to the Role of English Teachers in Extensive Reading. Heilongjiang Science and Technology Information, 16, 205.

[5] Zhao Ye. (2010). Analysis on the Disadvantages and Strategies of the Development of Students' Subjectivity in Network Education. Science and Education Journal, 11, 10-11.

Yu Peng was born in Sichuan province, China in 1987. He received his Master's degree in English language and literature from Sichuan Normal University, China in 2011.

$\mathrm{He}$ is currently a scholar and lecturer in the School of Foreign Languages, Sichuan University of Science \& Engineering, Sichuan, China. His research interests include English education and translation. 